\title{
Predictive Modelling of Wellhead Corrosion due to Operating Conditions: A Field Data Approach
}

\author{
Chinedu I. Ossai \\ Production Planning Department, Overall Forge Pty Ltd., 70 R W Henry Drive, Ettamogah near Albury, P.O. Box 5275, \\ Albury, NSW 2640, Australia \\ Correspondence should be addressed to Chinedu I. Ossai, ossaic@gmail.com
}

Received 3 October 2012; Accepted 19 November 2012

Academic Editors: M. Criado, M. Scendo, and R. Wang

Copyright (c) 2012 Chinedu I. Ossai. This is an open access article distributed under the Creative Commons Attribution License, which permits unrestricted use, distribution, and reproduction in any medium, provided the original work is properly cited.

The flow of crude oil, water, and gas from the reservoirs through the wellheads results in its deterioration. This deterioration which is due to the impact of turbulence, corrosion, and erosion significantly reduces the integrity of the wellheads. Effectively managing the wellheads, therefore, requires the knowledge of the extent to which these factors contribute to its degradation. In this paper, the contribution of some operating parameters (temperature, $\mathrm{CO}_{2}$ partial pressure, flow rate, and $\mathrm{pH}$ ) on the corrosion rate of oil and gas wellheads was studied. Field data from onshore oil and gas fields were analysed with multiple linear regression model to determine the dependency of the corrosion rate on the operating parameters. ANOVA, $P$ value test, and multiple regression coefficients were used in the statistical analysis of the results, while in previous experimental results, de Waard-Milliams models and de Waard-Lotz model were used to validate the modelled wellhead corrosion rates. The study shows that the operating parameters contribute to about $26 \%$ of the wellhead corrosion rate. The predicted corrosion models also showed a good agreement with the field data and the de Waard-Lotz models but mixed results with the experimental results and the de Waard-Milliams models.

\section{Introduction}

Corrosion of materials is a major challenge to maintaining the integrity of equipment in the industry. Mobile and static mechanical equipment like pipelines, vessels, tanks, compressors, turbines, and so forth have been periodically subjected to degradation and failure due to corrosion. According to reports [1], the cost of corrosion in the US will hit $6.2 \%$ of GDP in 2012, making it the most expensive single venture in the economy. The impact of corrosion in the oil and gas industry significantly contributes to the nonproductive time (NPT) of 20-30\% lost from exploration to production [2]. Corrosion of pipeline accounts for about $35 \%$ of failures associated with pipeline leakage and bursting in Canada [3], while $50 \%$ of the loss of containment hazard in Europe between 1980 and 2006 was a result of the ageing plant mechanism [4] triggered by corrosion-related fatigue cracking and erosion. Corrosion also ranks second to the highest most frequent initiating factor leading to loss of containment in UK $[4,5]$. While external corrosion, stress corrosion cracking, and microbiologically influenced corrosion have significantly resulted in pipeline failures, failure attributable to sour and sweet corrosion which results from activities of $\mathrm{CO}_{2}$ and $\mathrm{H}_{2} \mathrm{~S}$ has contributed to over $50 \%$ of all pipeline failures [3].

Over the decades, experts have worked to combat the menace of corrosion with varying degree of success. They have used many techniques that include use of alternative materials, modification of microstructures, addition of new elements to existing alloys of metals, use of chemical inhibitors, and linings; however, the act of corrosion has not been prevented from occurring. Corrosion has just continued to occur because materials are continually trying to return to the original energy state via lowering of their Gibb's energy [6].

Considering the overwhelming importance of pipelines in the oil and gas industry, the contribution of experts in combating the corrosion problem cannot be overemphasized. This is pertinent to the safeguarding of the environment, personnel, and cost associated with oil and gas production. The growth in the demand of oil and gas around the world has increased the need of exploration in unfriendly terrains like deep waters and the Antarctica. This has increased 
the pressure on the exploration equipment and consequently the pipeline which plays a major role in the transportation from the oil and gas reservoirs. The consequences of this pressure on pipelines and other equipment are overutilization, reduction in life cycles, and failures $[7,8]$.

To reduce the problem of corrosion and enhance pipeline integrity, corrosion experts have worked on different corrosion prediction models in a bid to identify the best way to determine corrosion in pipelines. Many authors have investigated the corrosion problem in oil and gas pipelines using electrochemical, mechanistic, semiempirical, empirical, hybrid, and probabilistic methods and so forth [916]. Their works have focused on knowing the contribution of different operating parameters in the oil and gas such as $\mathrm{CO}_{2}, \mathrm{H}_{2} \mathrm{~S}$, temperature, bacteria, and so forth on the entire corrosion process. Others investigated the impact of the mechanical process of fluid flow and associated effects of turbulence on corrosion of pipelines, well tubing, vessels, tanks, and so forth [17-19]. Despite the enormity of the work on corrosion, it is difficult to summarily prescribe a holistic solution to the corrosion process. This is because of the complex electrochemical and physical processes involved. The most important parameters that can enhance the result of corrosion prediction are those related to the steel properties, water chemistry, flow pattern, oil-versus-water wetting, and operating conditions [20]. This is why the works of numerous authors focused on them $[7,8,10,11,15,19-22]$.

Corrosion prediction models that were aimed at the multiphase flow regime, $\mathrm{pH}, \mathrm{H}_{2} \mathrm{~S}, \mathrm{CO}_{2}$, and so forth were used by some authors [20-22] to establish the extent of internal corrosion of pipelines at different operating conditions. This helped to establish the point where mitigation is necessary in order to reduce the level of risk that corrosion poses on the pipeline. Chemical inhibitors are injected in most instances to mitigate the effect of the corrodents; while in extreme cases, more severe measures like replacement of the pipeline with more resistant materials are considered. A lot of authors have numerous corrosion experimental results [11, $15,16,21,22]$ that were not verified with field conditions; this resulted in numerous laboratory results not having good practical relevance in the field. It is, therefore, important to understand the trend thatcorrosion field data follows with respect to the operating condition in order to enhance the acquisition of corrosion prediction results that will have high practical relevance. Though the works of the utilization of case-based reasoning (CBR) [23], and stochastic modelling for $\mathrm{CO}_{2}$ corrosion via metal loss and precipitation process [24] were excellent works, they have limited validation with field data. This made to have little application in the industry.

Many pipeline corrosion models failed to recognize the contribution of $\mathrm{H}_{2} \mathrm{~S}$, organic acids, and microorganisms in the corrosion process; however, some authors [25] built a comprehensive integrated $\mathrm{CO}_{2} / \mathrm{H}_{2} \mathrm{~S}$ corrosion multiphase flow model. The interaction of the experimental results with the field data made it possible for the authors to predict the critical velocity for entraining free water by the flowing oil. This result shows a good practical relevance for corrosion prediction of pipelines. In a bid to show the contribution of gas flow in pipeline corrosion, another researcher [26] applied a mechanistic model to predict the corrosion damage rate of distribution observed in oil wells operating within mature oil field. The work showed that $\mathrm{CO}_{2}$ can be quantitatively determined for a uniform corrosion in pipeline that resulted in localized attack.

Many other experimental results about the impact of $\mathrm{CO}_{2}, \mathrm{H}_{2} \mathrm{~S}$, temperature, $\mathrm{O}_{2}$, acetic acid, and bacteria on corrosion of carbon steel are found readily in the literature $[9-13,27,28]$. Temperature increase has been shown to increase corrosion rate until a particular threshold when the increase stops to affect corrosion $[22,29]$. The presence of $\mathrm{O}_{2}$ enhances the corrosion process, while $\mathrm{H}_{2} \mathrm{~S}$ has been shown to cause localized pitting corrosion in pipelines [27]. Acetic acid and other organic and inorganic acids also aid in the increasing of corrosion rate and initiation of localized corrosion and pitting $[30,31]$. Other authors utilized mechanistic modelling to predict corrosion rate in steel surfaces. This approach which involved homogenous chemical reaction, electrochemical reaction at the steel surface, and transportation of specie in the bulk solution was utilized by many authors in their prediction of $\mathrm{CO}_{2}$ corrosion rate $[11,21,32]$.

Due to the importance of wellheads in the transportation of oil and gas from the reservoir to the pipelines, it is necessary to maintain the integrity at all times; however, due to turbulence, corrosion, erosion, and other factors, they are continuously deteriorating in operation. To be able to understand more about this deterioration as a result of corrosion, the effect of certain operating parameters on the wellhead corrosion rates was studied.

In this study, historic field data of wellhead corrosion rates measured with ultrasonic thickness measurement (UTM) technique, temperature, $\mathrm{CO}_{2}$ partial pressure, flow velocity of crude oil, mixed flow velocity, and $\mathrm{pH}$ were used. The main objective of this research is to establish to which extent these operating parameters affect wellhead corrosion rate.

\section{Research Methodology}

Historical data from the company operating the Nigerian oil mining license (OML61) were obtained from the organization's historical records. The wellhead corrosion rates were determined by using the ultrasonic thickness measurement (UTM) technique, while the temperature, operating pressure, $\mathrm{pH}, \mathrm{CO}_{2}$ content, and production rates of oil, gas, and water were obtained as a routine well monitoring procedure. The flow rates of the fluids were obtained through calculation using the information from the parameters obtained. The summary of the data obtained is shown in Tables 1 and 2.

2.1. Model Development. The wellhead corrosion rate can be expressed as a function of the operating parameters of the production well according to the following:

$$
\begin{gathered}
\mathrm{CR}=f\left(T, P_{\mathrm{CO}_{2}}, V_{m}, \mathrm{pH}\right), \\
\mathrm{CR}=f\left(T, P_{\mathrm{CO}_{2}}, V\right),
\end{gathered}
$$


TABLE 1: Summary of oil, gas, and water production rates of the studied wells.

\begin{tabular}{lclr}
\hline Length of pipeline & $900-14650 \mathrm{~m}$ & Oil production rate & $23-249 \mathrm{~m}^{3} / \mathrm{day}$ \\
Pipeline external diameter & $0.114 \mathrm{~m}$ & Gas production rate & $0.006-0.497 \mathrm{SMm}^{3} / \mathrm{day}$ \\
Pipeline internal diameter & $0.09718 \mathrm{~m}$ & Water production rate & $0.12-1094.64 \mathrm{~m}^{3} / \mathrm{day}$ \\
\hline
\end{tabular}

TABLE 2: Summary of the field operating parameters at the wellheads.

\begin{tabular}{lccccccc}
\hline & $\mathrm{CR}(\mathrm{mm} / \mathrm{yr})$ & $T\left({ }^{\circ} \mathrm{C}\right)$ & $P_{\mathrm{CO}_{2}}(\mathrm{MPA})$ & $V_{m}(\mathrm{~m} / \mathrm{s})$ & $V(\mathrm{~m} / \mathrm{s})$ & $P_{\mathrm{op}}(\mathrm{MPA})$ & $\mathrm{pH}$ \\
\hline Mean & 0.545 & 61 & 0.203 & 0.447 & 0.158 & 8.62 & 7.65 \\
Standard deviation & 0.283 & 7.78 & 0.128 & 0.442 & 0.088 & 3.02 & 0.64 \\
\hline
\end{tabular}

$$
\begin{gathered}
\mathrm{CR}=f\left(T, P_{\mathrm{CO}_{2}}, V_{m}\right), \\
\mathrm{CR}=f\left(T, P_{\mathrm{CO}_{2}}\right),
\end{gathered}
$$

where $\mathrm{CR}=$ wellhead corrosion rate $(\mathrm{mm} / \mathrm{yr}), T=$ temperature $\left({ }^{\circ} \mathrm{C}\right), P_{\mathrm{CO}_{2}}=\mathrm{CO}_{2}$ partial pressure (mpa), $V_{m}=$ mixed velocity of fluid flowing through the wellhead $(\mathrm{m} / \mathrm{s})$, and $V$ = flow velocity of the crude oil $(\mathrm{m} / \mathrm{s})$.

To model the effect of the listed operating parameters on the corrosion rate of the wellhead, a linear regression model is adopted. The regression equation that is used to predict the impact of the operating parameters on the wellhead corrosion rate (due to the combination of these operating parameters) is shown in $(2 \mathrm{a})-(2 \mathrm{~d})$ :

$$
\begin{gathered}
\mathrm{CR}=\alpha_{11}+\beta_{11} T+\beta_{12} P_{\mathrm{CO}_{2}}+\beta_{13} V_{m}+\beta_{14} \mathrm{pH}, \\
\mathrm{CR}=\alpha_{21}+\beta_{21} T+\beta_{22} P_{\mathrm{CO}_{2}}+\beta_{23} V, \\
\mathrm{CR}=\alpha_{31}+\beta_{31} T+\beta_{31} P_{\mathrm{CO}_{2}}+\beta_{32} V_{m}, \\
\mathrm{CR}=\alpha_{41}+\beta_{41} T+\beta_{42} P_{\mathrm{CO}_{2}},
\end{gathered}
$$

where $\alpha_{i k}$ and $\beta_{i k}$ are the normal and slope coefficients due to the operating parameters $\left(T, \mathrm{pH}, V, V_{m}\right.$, and $\left.P_{\mathrm{CO}_{2}}\right)$

Equations (2a)-(2d) can be written as a single matrix equation as shown in (1). Consider

$$
\underset{(n+1)}{y}=\underset{(n \times k+1)(k+1 \times 1)}{x \beta},
$$

where $x=\left(T, P_{\mathrm{CO}_{2}}, V_{m}, V\right.$, or $\left.\mathrm{pH}\right), y=\left(\mathrm{CR}_{1}, \mathrm{CR}_{2}, \ldots\right.$, $\left(\mathrm{R}_{n}\right)^{\prime}$ is a vector of measured wellhead corrosion rates at different levels of the operating parameters ( $x$ variables).

The matrix form of the operating parameters is shown to be in the form of

$$
x=\left[\begin{array}{cccc}
1 & x_{11} & \ldots & x_{1 k} \\
1 & x_{21} & \ldots & x_{2 k} \\
1 & x_{n 1} & \ldots & x_{n k}
\end{array}\right]
$$

$\beta=\left(\alpha, \beta_{1}, \beta_{2}, \ldots, \beta_{k}\right)^{\prime}$ and contains the regression coefficients due to the operating parameters.
Solving for the residual sum of squares by introducing an error factor $(e)$ to $(2 \mathrm{a})-(2 \mathrm{~d})$, a normal least equation of the form shown in (3) is obtained as follows:

$$
\begin{gathered}
x^{\prime} x \beta=x y^{\prime}, \\
x^{\prime} x=\left[\begin{array}{ccccc}
n & \sum x_{i 1} & \sum x_{i 2} & \ldots & \sum x_{i k} \\
\sum x_{i 1} & \sum x_{i 1}^{2} & \sum x_{i 1} x_{i 2} & \ldots & \sum x_{i 1} x_{i k} \\
\sum x_{i 2} & \sum x_{i 1} x_{i 2} & \sum x_{i 2}^{2} & \ldots & \sum x_{i 2} x_{i k} \\
\vdots & \vdots & \vdots & \vdots & \vdots \\
\sum x_{i k} & \sum x_{i 1} x_{i k} & \sum x_{i 2} x_{i k} & \ldots & \sum x_{i k}^{2}
\end{array}\right], \\
x y^{\prime}=\left[\begin{array}{c}
\sum y_{i} \\
\sum x_{i 1} y_{i} \\
\sum x_{i 2} y_{i} \\
\vdots \\
\sum x_{i k} y_{i}
\end{array}\right] .
\end{gathered}
$$

The solution of the normal equation (3) gives the solution of the independent coefficients of the operating parameters. This is given as follows:

$$
\beta=\left(x^{\prime} x\right)^{-1} x y^{\prime} .
$$

Multiple regression and analysis of variance (ANOVA) test was performed at $95 \%$ confidence level to examine the combined effect of temperature, $\mathrm{CO}_{2}$ partial pressure, flow velocity, and $\mathrm{pH}$ on wellhead corrosion rate of the studied oil fields.

2.2. Validation of the Model. To test the accuracy of these models, three out of the thirty-three field data obtained from OML61, de Waard and Milliams model (DM) [13], modified de Waard and Milliams model (MDM) [9], de Waard and Lotz model (DL) [12], and experimental results of Zhou and Jepson (1993), Jepson and Menezes (1994), and Bhongale et al. (1996) from the NSF/IUCRC multiphase system centre (as reported by Zhang et al. (1997) [21]) were used.

2.3. De Waard and Milliams Model. This is one of the oldest known mechanistic models for predicting $\mathrm{CO}_{2}$ corrosion. This model is based on the electrochemical studies carried out by de Waard and Milliams to show the correlation 
between temperature $\left({ }^{\circ} \mathrm{C}\right), \mathrm{CO}_{2}$ partial pressure, and corrosion rate $(\mathrm{mm} / \mathrm{yr})$. The equation for the $\mathrm{CO}_{2}$ corrosion rate is shown as follows:

$$
\begin{aligned}
\log \left(\mathrm{CR}_{t}\right)= & 7.96-\frac{2320}{T+273} \\
& -5.55 \times 10^{-3} T+0.67 \log \left(P_{\mathrm{CO}_{2}}\right),
\end{aligned}
$$

where: $\mathrm{CR}_{t}=$ corrosion rate $(\mathrm{mm} / \mathrm{yr}), T=$ temperature $\left({ }^{\circ} \mathrm{C}\right)$, $P_{\mathrm{CO}_{2}}=\mathrm{CO}_{2}$ partial pressure (mpa).

De Waard and Milliams revised the constants of the formula in (7) based on the experimental results of Dugstad et al. (1994) [10] and obtained the following expression:

$$
\log \left(\mathrm{CR}_{t}\right)=5.8-\frac{1710}{T+273}+0.67 \log \left(P_{\mathrm{CO}_{2}}\right) .
$$

To further validate this model, de Waard and Lotz modelled corrosion rate with respect to velocity in the absence of surface scale with a parallel resistance model [12]. The result of their experimental analysis is summarized in (9) the following:

$$
\frac{1}{V_{\mathrm{cr}}}=\frac{1}{V_{r}}+\frac{1}{V_{m}},
$$

where $V_{\text {cr }}=$ corrosion rate, $V_{r}=$ flow-independent contribution denoting the reaction rate, and $V_{m}=$ flow-dependent contribution denoting the mass transfer rate as follows:

$$
\log \left(V_{r}\right)=4.93-\frac{1119}{T+273}+0.58 \log \left(P_{\mathrm{CO}_{2}}\right)
$$

where $T=$ temperature $\left({ }^{\circ} \mathrm{C}\right)$, and $P_{\mathrm{CO}_{2}}=\mathrm{CO}_{2}$ partial pressure (mpa). Consider

$$
V_{m}=2.45 \frac{U^{0.8}}{D_{h}^{0.8}} P_{\mathrm{CO}_{2}},
$$

where $U=$ liquid flow rate $(\mathrm{m} / \mathrm{s})$, and $D_{h}=$ hydraulic diameter of the pipe.

\section{Results and Discussions}

The correlation results of the corrosion rate in the wellhead as a dependent variable and the operating parameters $(T$, $\mathrm{pH}, V_{m}, V$, and $P_{\mathrm{CO}_{2}}$ ) are shown in Table 3.

The correlation coefficient $R^{2}$ ranges from 0.168 to 0.336 , while the adjusted $R^{2}$ ranges from 0.106 to 0.259 . This result implies that only $10.6 \%$ of the effect of temperature and $\mathrm{CO}_{2}$ partial pressure contributed to the corrosion rate on the oil field wellheads when the corrosion rate was determined as a function of only the two parameters, while $25.9 \%$ of wellhead corrosion was caused by the combined effect of temperature, $\mathrm{CO}_{2}$ partial pressure, oil flow rate, and $\mathrm{pH}$ of the associated formation of water in the mixture.

The field data showed significance at $F$ values of $0.045,0.013$, and 0.026 for wellhead corrosion rates with the following combination of operating parameters: $\mathrm{CR}(T$, $\left.P_{\mathrm{CO}_{2}}, \mathrm{pH}, V_{m}\right), \mathrm{CR}\left(T, P_{\mathrm{CO}_{2}}, V\right)$, and $\mathrm{CR}\left(T, P_{\mathrm{CO}_{2}}, V_{m}\right)$, while $F$ is not significant at 0.083 for $\mathrm{CR}\left(T, P_{\mathrm{CO}_{2}}\right)$ at $95 \%$ confidence level as shown in Table 4.
This could imply that only the corrosion rate determined using temperature and $\mathrm{CO}_{2}$ partial pressure is not statistically significant; however, the result shown in Table 3 for adjusted square of correlation coefficient $R^{2}$ shows that none of the combinations is statistically significant due to the low effects of the operating parameters on the wellhead corrosion rate.

The $P$ value of the variables shows that the coefficients of the operating parameters have values higher than the 0.05 for all the variables as shown in Table 5 .

This is a further proof that the test is not statistically significant. Though some of the studied operation parameters $\mathrm{CR}\left(T, P_{\mathrm{CO}_{2}}, \mathrm{pH}, V_{m}\right), \mathrm{CR}\left(T, P_{\mathrm{CO}_{2}}, V\right)$, and $\mathrm{CR}\left(T, P_{\mathrm{CO}_{2}}, V_{m}\right)$ were statistically significant with the result of ANOVA in Table 4 , the $P$ value and square of correlation coefficient $\left(R^{2}\right)$ show statistical insignificance. This result could imply that the effect of other electrochemical, chemical, and mechanical activities associated with the flow of the fluid might have also affected the corrosion rate. The activities of bacteria and the organic and inorganic compounds could have also affected the corrosion rate as was pointed by some of these authors [30, 33-35]. Another possible cause of minimal effect of the operating parameters on the wellhead corrosion rate is the bubbles production effect of multiphase flow system due to turbulence in the flow regime. This is supported by the research on the effect of bubbles on mass transfer in multiphase flow [32].

The coefficients of the operating parameters in Table 5 were used to develop the set of linear regression equations in (12) -(15) for wellhead corrosion rate as follows:

$$
\begin{aligned}
& \mathrm{CR}=3.8 \times 10^{-3} \mathrm{~T}+9.97 \times 10^{-1} \mathrm{P}_{\mathrm{CO}_{2}}+2.379 \times 10^{-1} V_{m} \\
& +5.97 \times 10^{-2} \mathrm{pH}-4.508 \times 10^{-1} \text {, } \\
& \mathrm{CR}=4.1 \times 10^{-3} \mathrm{~T}+9.48 \times 10^{-1} P_{\mathrm{CO}_{2}} \\
& +2.32 \times 10^{-1} V_{m}-9.1 \times 10^{-4} \\
& \mathrm{CR}=3.196 \times 10^{-3} \mathrm{~T}+8.196 \times 10^{-1} \mathrm{P}_{\mathrm{CO}_{2}} \\
& +1.333 V-2.61 \times 10^{-2} \text {, } \\
& \mathrm{CR}=7.01 \times 10^{-2}+5.138 \times 10^{-3} \mathrm{~T}+7.97 \times 10^{-1} P_{\mathrm{CO}_{2}} \text {. }
\end{aligned}
$$

The modeled result for wellhead corrosion rate due to temperature, $\mathrm{CO}_{2}$ partial pressure, $\mathrm{pH}$, and mixed flow rate (see (12)) was compared with field data, and the result is shown in Figure 1.

The result shows that there are some similarities between the modelled result and field data. Whereas the field data ranges from 0.06 to $0.51 \mathrm{~mm} / \mathrm{yr}$, the modelled result ranged from 0.13 to $0.38 \mathrm{~mm} / \mathrm{yr}$. This result shows that there is a reasonable degree of agreement between the field data and the modelled prediction results.

The result of wellhead corrosion rate as a function of temperature, $\mathrm{CO}_{2}$ partial pressure, and mixed flow velocity of the fluid (see (13)) was compared with experimental results of Zhou and Jepson (1993), Jepson and 
TABLE 3: Summary of the results of regression analysis.

\begin{tabular}{lcccc}
\hline Operating parameter & Multiple $R$ & $R^{2}$ & Adjusted $R^{2}$ & Standard error \\
\hline $\mathrm{CR}\left(T, P_{\mathrm{CO}_{2}}\right)$ & 0.4099 & 0.1680 & 0.1064 & 0.2677 \\
$\mathrm{CR}\left(T, P_{\mathrm{CO}_{2}}, V_{m}\right)$ & 0.5428 & 0.2946 & 0.2132 & 0.2511 \\
$\mathrm{CR}\left(T, P_{\mathrm{CO}_{2}}, V\right)$ & 0.5793 & 0.3356 & 0.2589 & 0.2437 \\
$\mathrm{CR}\left(T, P_{\mathrm{CO}_{2}}, \mathrm{pH}, V_{m}\right)$ & 0.5589 & 0.3123 & 0.2023 & 0.2529 \\
\hline
\end{tabular}

TABLE 4: Summary of ANOVA for wellhead corrosion and operating parameters.

\begin{tabular}{|c|c|c|c|c|c|c|}
\hline Measured parameters & & df & SS & MS & $F$ & Significance $F$ \\
\hline \multirow{3}{*}{$\mathrm{CR}\left(T, P_{\mathrm{CO}_{2}}, \mathrm{pH}, V_{m}\right)$} & Regression & 4 & 0.72610 & 0.1815 & 2.8385 & \multirow{3}{*}{0.045} \\
\hline & Residual & 25 & 1.59877 & 0.0640 & & \\
\hline & Total & 29 & 2.32487 & & & \\
\hline \multirow{3}{*}{$\mathrm{CR}\left(T, P_{\mathrm{CO}_{2}}, V\right)$} & Regression & 3 & 0.78025 & 0.2601 & 4.3779 & \multirow{3}{*}{0.012709} \\
\hline & Residual & 26 & 1.54462 & 0.0594 & & \\
\hline & Total & 29 & 2.32487 & & & \\
\hline \multirow{3}{*}{$\mathrm{CR}\left(T, P_{\mathrm{CO}_{2}}, V_{m}\right)$} & Regression & 3 & 0.68499 & 0.2283 & 3.6201 & \multirow{3}{*}{0.026244} \\
\hline & Residual & 26 & 1.63988 & 0.0631 & & \\
\hline & Total & 29 & 2.32487 & & & \\
\hline \multirow{3}{*}{$\mathrm{CR}\left(T, P_{\mathrm{CO}_{2}}\right)$} & Regression & 2 & 0.39064 & 0.1953 & 2.7265 & \multirow{3}{*}{0.083462} \\
\hline & Residual & 27 & 1.93423 & 0.0716 & & \\
\hline & Total & 29 & 2.32487 & & & \\
\hline
\end{tabular}

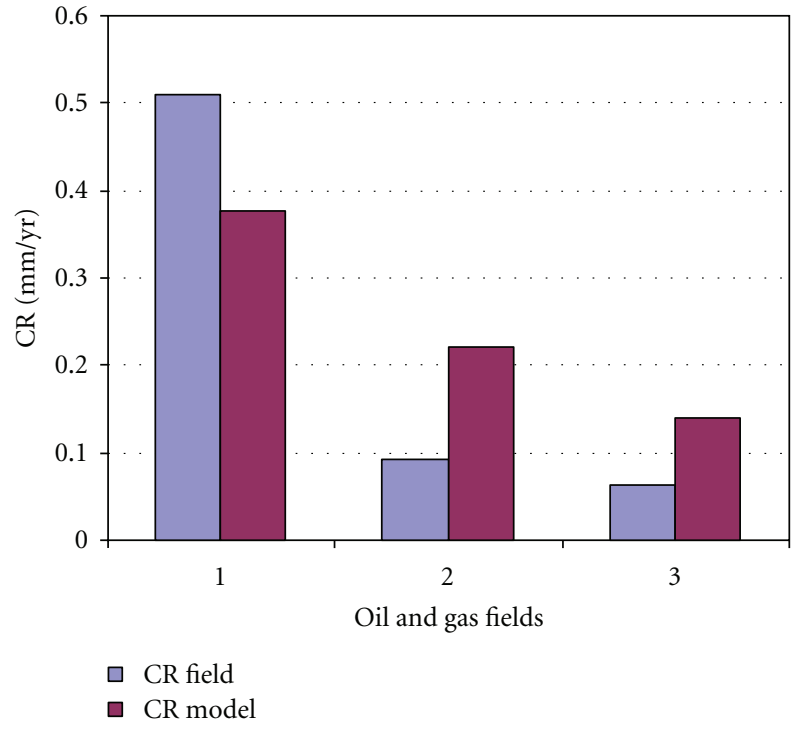

Figure 1: Wellhead corrosion rate in the field versus the model.

Menezes (1994), Bhongale et al. (1996). This result was reported by Zhang et al. [21]. The summary of the results comparison is shown in Table 6 .

The result shows that there is variation between the experimental results and the prediction model across the range of mixed velocity and $\mathrm{CO}_{2}$ partial pressure.

The same set of experimental results reported by Zhang et al. (1997) [21] was used to compare the result of the model using (14) in Table 7. The result shows that the modelled results and the experimental results have a mixed

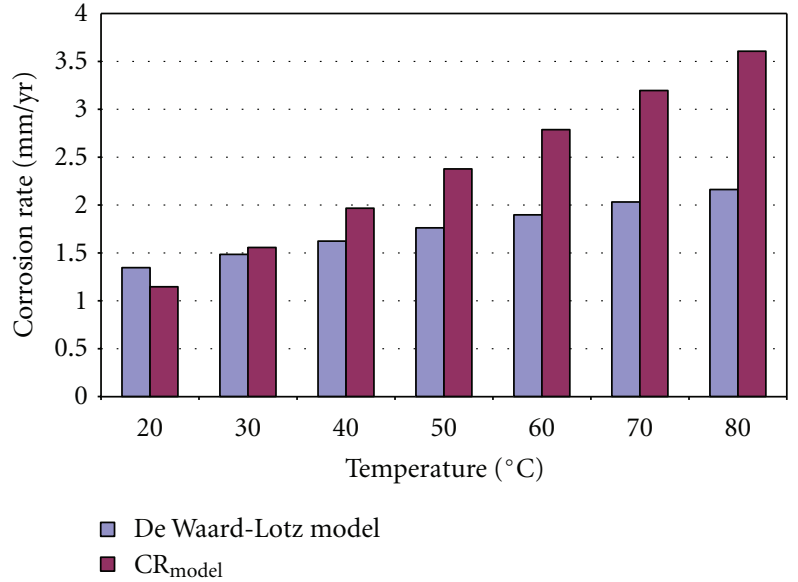

Figure 2: Summary of modelled wellhead corrosion rate and de Waard-Lotz Model $P_{\mathrm{CO}_{2}}=0.1 \mathrm{mpa}, V=1 \mathrm{~m} / \mathrm{s}$.

relationship across the various $\mathrm{CO}_{2}$ partial pressure and oil flow velocity.

The model reasonably predicted the corrosion rate with a small degree of variance at lower $\mathrm{CO}_{2}$ partial pressure and higher flow velocity with modelled corrosion rate higher than the experimental corrosion rate at $P_{\mathrm{CO}_{2}}=0.136 \mathrm{mpa}$ and $V=1-1.8 \mathrm{~m} / \mathrm{s}$. The prediction was much lower than the experimental values at lower velocity and higher $\mathrm{CO}_{2}$ partial pressure. The result of the model equation (14) also showed a good agreement with de Waard-Lotz model [12] as shown in Figure 2.

For temperature between $30-80^{\circ} \mathrm{C}, 0.1 \mathrm{MPA}$, and velocity of $1 \mathrm{~m} / \mathrm{s}$, the predicted model gave a corrosion rate that 
TABLE 5: Summary of parameter estimate.

\begin{tabular}{|c|c|c|c|c|c|c|}
\hline Variable & Coefficient & Standard error & $P$ value & $t$-test & Lower 95\% & Upper $95 \%$ \\
\hline$\beta_{41}$ & 0.0038 & 0.0062 & 0.6098 & 0.5475 & -0.009 & 0.0165 \\
\hline$\beta_{42}$ & 0.997 & 0.386 & 2.585 & 0.016 & 0.2028 & 1.7927 \\
\hline$\beta_{43}$ & 0.2379 & 0.1085 & 2.1922 & 0.0379 & 0.0144 & 0.4614 \\
\hline$\beta_{44}$ & 0.0597 & 0.0745 & 0.8018 & 0.4302 & -0.0937 & 0.2132 \\
\hline$\alpha_{45}$ & -0.4508 & 0.6738 & -0.669 & 0.5097 & -1.8386 & 0.937 \\
\hline$\beta_{21}$ & 0.0041 & 0.00613 & 0.668308 & 0.509827 & -0.0085 & 0.016697 \\
\hline$\beta_{22}$ & 0.948 & 0.378337 & 2.505766 & 0.01881 & 0.170341 & 1.725707 \\
\hline$\beta_{23}$ & 0.2323 & 0.107545 & 2.160294 & 0.040147 & 0.011267 & 0.453389 \\
\hline$\beta_{31}$ & 0.003196 & 0.005979 & 0.534545 & 0.597507 & -0.00909 & 0.015486 \\
\hline$\beta_{32}$ & 0.8196 & 0.360991 & 2.270454 & 0.031701 & 0.077586 & 1.561642 \\
\hline$\beta_{33}$ & 1.3327 & 0.520421 & 2.560891 & 0.016593 & 0.263001 & 2.402483 \\
\hline$\alpha_{31}$ & -0.0261 & 0.360199 & -0.07247 & 0.942781 & -0.76651 & 0.714296 \\
\hline$\alpha_{11}$ & 0.0701 & 0.393384 & 0.17819 & 0.859904 & -0.73706 & 0.877254 \\
\hline$\beta_{11}$ & 0.0051 & 0.006513 & 0.788925 & 0.437029 & -0.00822 & 0.018501 \\
\hline$\beta_{12}$ & 0.7973 & 0.396294 & 2.011877 & 0.05431 & -0.01583 & 1.610425 \\
\hline$\alpha_{21}$ & -0.0009 & 0.370577 & -0.00245 & 0.998066 & -0.76264 & 0.760825 \\
\hline
\end{tabular}

TABLE 6: Summary of experimental result and modelled equation of wellhead corrosion rate using mixed flow velocity $\left(V_{m}\right), \mathrm{CO}_{2}$ partial pressure, and temperature $\left[T=40^{\circ} \mathrm{C}\right]$.

\begin{tabular}{lccc}
\hline $\mathrm{CO}_{2}$ partial pressure & $\begin{array}{c}\text { Mixed velocity } \\
V_{m}(\mathrm{~m} / \mathrm{s})\end{array}$ & $\begin{array}{c}\text { Experiment } \\
\mathrm{CR}_{\mathrm{EXP}}\end{array}$ & $\begin{array}{c}\text { Modelled } \\
\mathrm{CR}_{\text {model }}\end{array}$ \\
\hline 0.27 & 0.28 & 4 & 1.96001 \\
0.27 & 0.56 & 4.9 & 2.02497 \\
0.27 & 1 & 5.4 & 2.12705 \\
0.45 & 0.28 & 6.25 & 2.13065 \\
0.45 & 0.56 & 7.4 & 2.19561 \\
0.45 & 1 & 7.9 & 2.29769 \\
0.79 & 0.28 & 9.2 & 2.45297 \\
0.79 & 0.56 & 10.75 & 2.45297 \\
0.79 & 1 & 11.6 & 2.62001 \\
\hline
\end{tabular}

is generally slightly higher than that predicted with the de Waard-Lotz model, while at $20^{\circ} \mathrm{C}$, the corrosion rate predicted by de Waard-Lotz model is slightly higher than that predicted by the predicted model. The range of prediction for the prediction model is $1.15-3.61 \mathrm{~mm} / \mathrm{yr}$, while that of de Waard-Lotz model is $1.34-2.16 \mathrm{~mm} / \mathrm{yr}$.

Figure 3 shows that as the temperature increases, the predicted wellhead corrosion model (see (15)) increases as both well as de Waard-Milliams model [13] and the modified de Waard and Milliams model [12]. At temperature of $20-80^{\circ} \mathrm{C}$, the predicted wellhead corrosion rate ranges from $0.253-$ $0.561 \mathrm{~mm} / \mathrm{yr}$, the de Waard-Milliams model ranges from 0.448 to $0.469 \mathrm{~mm} / \mathrm{yr}$, while the modified de Waard-Milliams model shows a range of $0.391-1.077 \mathrm{~mm} / \mathrm{yr}$.
TABLE 7: Summary of experimental result and modelled equation of wellhead corrosion rate using crude flow velocity $(V), \mathrm{CO}_{2}$ partial pressure, and temperature $\left[T=40^{\circ} \mathrm{C}\right]$.

\begin{tabular}{lccc}
\hline $\mathrm{CO}_{2}$ partial pressure & Oil flow rate & $\begin{array}{c}\text { Experiment } \\
\mathrm{CR}_{\exp } \\
(\mathrm{mm} / \mathrm{yr})\end{array}$ & $\begin{array}{c}\text { Modelled } \\
\mathrm{CR}_{\text {pred }}(\mathrm{MPA})\end{array}$ \\
\hline 0.136 & 1 & 0.88 & 1.54595 \\
0.136 & 1.3 & 1.23 & 1.945772 \\
0.136 & 1.8 & 1.75 & 2.612143 \\
0.27 & 0.18 & 2.9 & 0.562929 \\
0.27 & 0.28 & 3 & 0.696204 \\
0.27 & 1 & 4.25 & 1.655778 \\
0.45 & 0.18 & 3.4 & 0.71046 \\
0.45 & 0.28 & 5.6 & 0.843734 \\
0.45 & 1 & 8.6 & 1.803308 \\
0.79 & 0.18 & 5.6 & 0.989129 \\
0.79 & 1 & 11.4 & 2.081977 \\
\hline
\end{tabular}

\section{Conclusion}

The effect of the operating parameters (temperature, $\mathrm{CO}_{2}$ partial pressure, $\mathrm{pH}$, and flow rate) on the rate of corrosion of oil and gas wellheads was studied using regression modelling of historical field data. The study shows that about $26 \%$ of wellhead corrosion is caused by these operating parameters. Other factors that could have an impact on wellhead corrosion rate are organic and inorganic acids, bacteria, turbulence, erosion, erosion-corrosion, bubbles formation, and condensation resulting from the flow of the oil and gas [18, 32, 34-37]. 


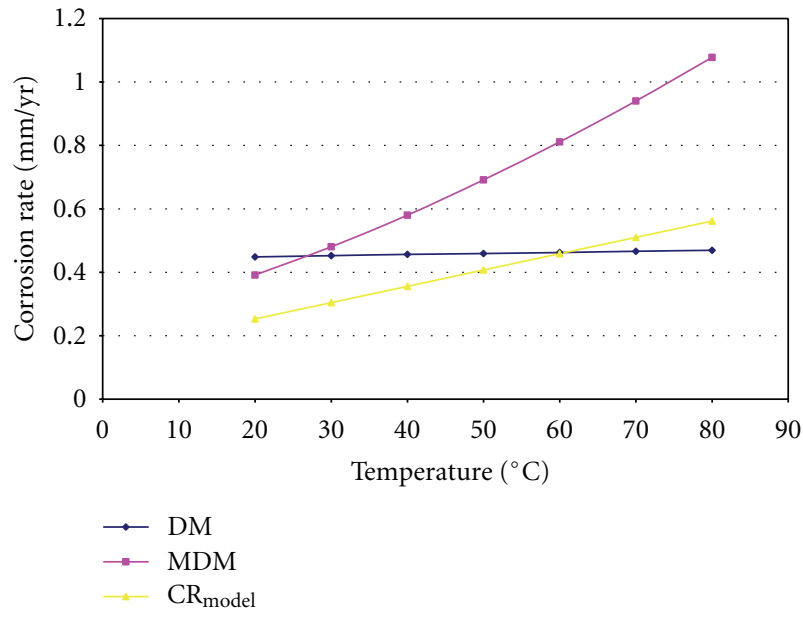

FIGURE 3: Summary of modelled wellhead corrosion rate, de WaardMilliams model and Modified de Waard Milliams model $\left(P_{\mathrm{CO}_{2}}=\right.$ $0.1 \mathrm{mpa})$.

The predicted corrosion model was validated with field data, experimental results, and de Waard-Milliams corrosion models. The result showed a good agreement between the field data and mixed results of both the experimental and de Waard-Milliams models.

\section{References}

[1] "Cost of Corrosion to Exceed \$1 Trillion in the United States in 2012 - G2MT Labs-The Future of Materials Condition Assessment," http://www.g2mtlabs.com/2011/06/nacecost-of-corrosion-study-update/.

[2] R. Nicholson, J. Feblowitz, C. Madden, and R. Bigliani, "The Role of Predictive Analytics in Asset Optimization for the Oil and Gas Industry-White Paper," 2010, http://www .tessella.com/wp-content/uploads/2008/02/IDCWP31SA4Web .pdf.

[3] CAPP, "Best Management Practices: Mitigation of Internal Corrosion in Oil Effluent Pipeline Systems," 2009, http:// www.capp.ca/getdoc.aspx?DocId=155641\&DT=PDF.

[4] Control of Major Accident Hazards, "Ageing Plant Operational Delivery Guide," http://www.hse.gov.uk/comah/guidance/ageing-plant-core.pdf.

[5] P. Horrocks, D. Mansfield, K. Parker, J. Thomson, T. Atkinson, and J. Worsley, "Managing Ageing Plant," http://www .hse.gov.uk/research/rrpdf/rr823-summary-guide.pdf.

[6] J. Kruger, "Electrochemistry of Corrosion," 2001, http://electrochem.cwru.edu/encycl/art-c02-corrosion.htm.

[7] "Review of corrosion management for offshore oil and gas processing," HSE Offshore Technology Report 2001/044, 2001.

[8] P.O. Gartland and R. Johnsen, "Application of internal corrosion modelling in risk assessment of pipeline," NACE International Conference Sereis, Corrosion 2003 paper no 03179, 2003.

[9] C. De-Waard and V. Lotz, "Prediction of $\mathrm{CO}_{2}$ corrosion of carbon steel," NACE International Conference Sereis, Corrosion /93. Paper no. 69, NACE int., Houston, Tex, USA, 1993.

[10] A. Dugstad, L. Lunde, and K. Videm, "Parametric study of $\mathrm{CO}_{2}$ corrosion of carbon steeel," NACE International Conference Sereis, Corrosion/94. Paper no 14, NACE, Houston, Tex, USA, 1994.
[11] M. Nordsveen, S. Nešić, R. Nyborg, and A. Stangeland, "A mechanistic model for carbon dioxide corrosion of mild steel in the presence of protective iron carbonate films-part 1: theory and verification," Corrosion, vol. 59, no. 5, pp. 443-456, 2003.

[12] C. de Waard, U. Lotz, and A. Dugstad, "Influence of liquid flow velocity on $\mathrm{CO}_{2}$ corrosion a semi-empirical model," NACE International Conference Sereis, Corrosion/95, paper no. 128, Houston, Tex, USA, 1995.

[13] C. De Waard and D. E. Milliams, "Cabonic acid corrosion of steel," Corrosion, vol. 31, no. 5, pp. 177-181, 1975.

[14] R. Nyborg, "Controlling internal corrosion in oil and gas pipeline," Business Briefing-Exploration \& Production, vol. 2005, no. 2, pp. 70-74, 2005.

[15] W. Sun and S. Nesic, "A mechanistic model of H2S corrosion of mild steel," NACE International Conference Sereis, CORROSION 2007 paper 07655, 2007.

[16] K.-L. Lee and S. Nesic, "EIS investigation on the electrochemistry of $\mathrm{CO}_{2} / \mathrm{H} 2 \mathrm{~S}$ corrosion," NACE International Conference Sereis, CORROSION 2004 paper 04728, 2004.

[17] M. E. Mohyaldinn, N. Elkhatib, and M. C. Ismail, "A computational tool for erosion/corrosion prediction in oil/gas production facilities," in Proceedings of the ICSSST2010 3rd International Conference on Solid State Science \&Technology, Kuching, Sarawak, Malaysia, 2010.

[18] S. Nesic and J. Postlethwaite, "Relationship between the structure of disturbed flow and erosion-corrosion," Corrosion, vol. 46, no. 11, pp. 874-880, 1990.

[19] S. Hassani, K. P. Roberts, S. A. Shirazi, J. R. Shadley, E. F. Rybicki, and C. Joia, "Flow loop study of chloride concentration effect on erosion, corrosion and erosion-corrosion of carbon steel in $\mathrm{CO}_{2}$ saturated systems," Corrosion, vol. 68, no. 2, 2012.

[20] A. Dugstad, E. Gulbrandesen, J. Kvarekvål, R. Nyborg, and M. Seiersten, "Corrosion testing in multiphase flow, challenges and limitations," NACE International Conference Sereis, Corrosion/2006 paper no 06598, 2006.

[21] R. Zhang, M. Gopal, and W. P. Jepson, "Development of a Mechanistic model for predicting Corrosion rate in Multiphase oil/water/gas flows," NACE International Conference Sereis, Corrosion /97, paper 601, 1997.

[22] W. P. Jepson, S. Bhongale, and M. Gopal, "Predictive model for sweet corrosion in horizontal multiphase slug flow," NACE International Conference Sereis, Corrosion/96: paper 19, 1996.

[23] B. Khajotia, D. Sormaz, and S. Nesic, "Case-based reasoning model of $\mathrm{CO}_{2}$ corrosion based on field data," NACE International Conference Sereis, CORROSION 2007 paper 07553, 2007.

[24] Y. Xian and S. Nesic, "A stochastic prediction model of localized $\mathrm{CO}_{2}$ corrosion," NACE International Conference Sereis, CORROSION 2005 paper No 05057, 2005.

[25] N. Srdjan, J. Cai, and K. L. John Lee, "A multiphase flow and internal corrosion prediction model for mild steel pipeline," NACE International Conference Sereis, CORROSION 2005 PAPER 05556, 2005.

[26] R. Case, "Assessment of $\mathrm{CO}_{2}$ corrosion damage distribution in Oil wells by deterministic and Stochastic Modelling," NACE International Conference Sereis, Corrosion/2008. Paper 08514, 2008.

[27] H. Fang, B. Brown, and S. Nescaronicacute, "Effects of sodium chloride concentration on mild steel corrosion in slightly sour environments," Corrosion, vol. 67, no. 1, 2011. 
[28] M. Singer, B. Brown, A. Camacho, and S. Nešić, "Combined effect of carbon dioxide, hydrogen sulfide, and acetic acid on bottom-of-the-line corrosion," Corrosion, vol. 67, no. 1, 2011.

[29] Y. Song, A. Palencsár, G. Svenningsen, J. Kvarekvål, and T. Hemmingsen, "Effect of $\mathrm{O}_{2}$ and temperature on sour corrosion," Corrosion, vol. 68, no. 7, pp. 662-671, 2012.

[30] V. Fajardo, C. Canto, B. Brown, and S. Nesic, "Effect of organic acids in $\mathrm{CO}_{2}$ corrosion," NACE Internatinal Conference \& Expo. CORROSION 2007 paper 07319, 2007.

[31] C. Mendex, M. Singer, A. Camacho, S. Hernndez, and S. Nesic, "Effect of acetic acid pH and MEG on $\mathrm{CO}_{2}$ top of the line corrosion," NACE International Conference Sereis, Corrosion 2005, paper 05278, 2005.

[32] H. Wang, W. Paul Jepson, J. Y. Cai, and M. Gopal, "Effect of bubbles on mass transfer in multiphase flow," NACE International Conference Sereis, CORROSION 2000 paper 00050, 2005.

[33] X. Hu, A. Neville, J. Wells, and V. De Souza, "Prediction of erosion-corrosion in oil and gas-a systematic approach," NACE International Conference Sereis, CORROSION 2008 paper 08540, 2008.

[34] A. A. Sami and A. A. Mohammed, "Study synergy effect on erosion-corrosion in oil and gas pipelines," Engineering \& Technology, vol. 26, no. 9, 2008.

[35] J. Wen, T. Gu, and S. Nesic, "Investigation of the effects of fluid flow on srb biofilm," NACE International Corrosion Conference Series, Corrosion/2007 Paper no 07516, 2007.

[36] A. Keating and S. Nesic, "Prediction of two-phase erosion-corrosion in bends," in Proceedings of the 2nd International Conference on CFD in Minerals and Processes Industries CSIRO, Melbourne, Australia, 1999.

[37] S. Hassani, K. P. Roberts, S. A. Shirazi, J. R. Shadley, E. F. Rybicki, and C. Joia, "Flow loop study of chloride concentration effect on erosion, corrosion and erosion-corrosion of carbon steel in $\mathrm{CO}_{2}$ saturated systems," Corrosion, vol. 68, no. 2, 2012 . 

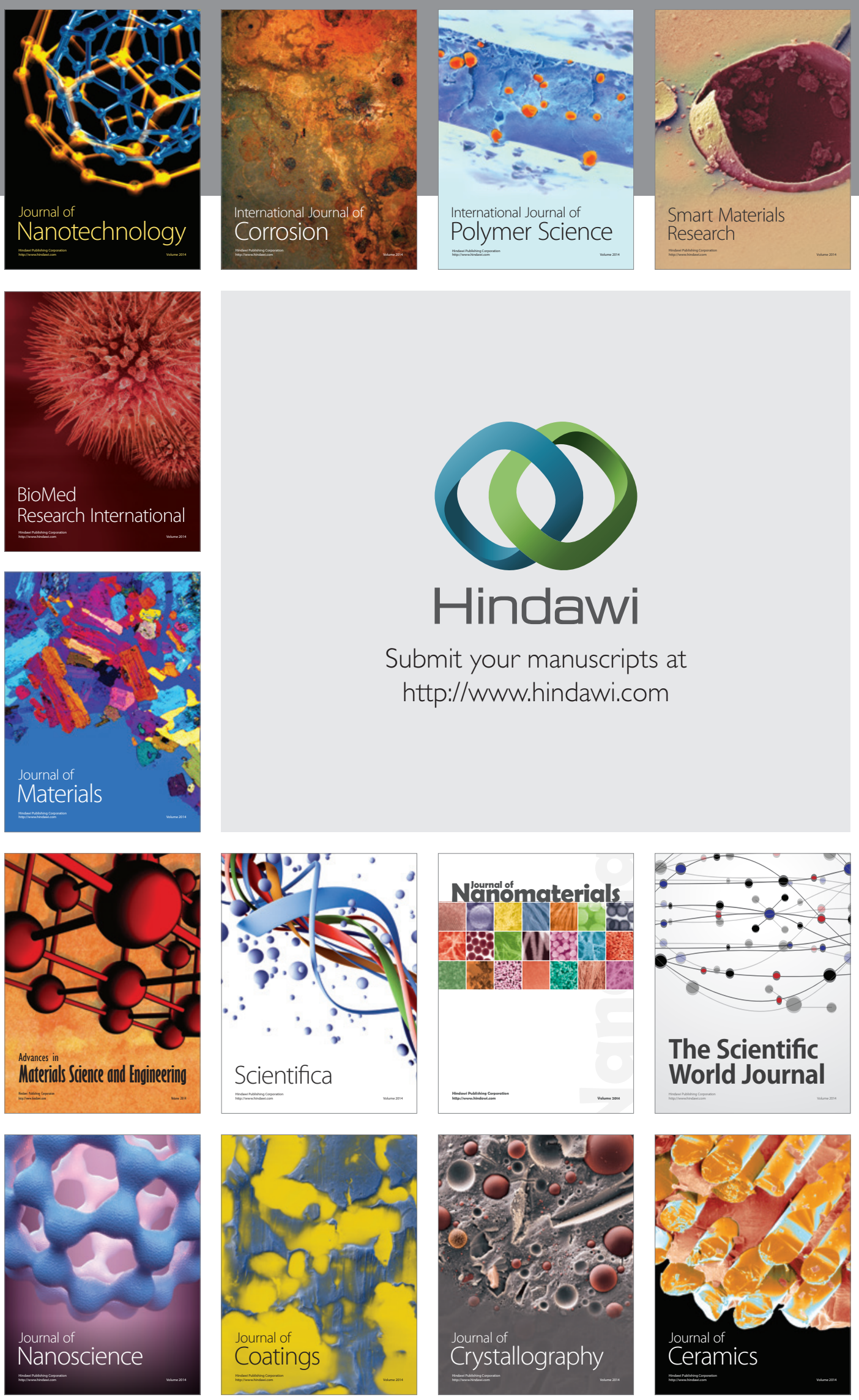

The Scientific World Journal

Submit your manuscripts at

http://www.hindawi.com

\section{World Journal}

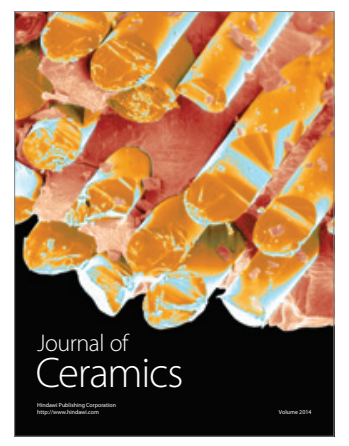

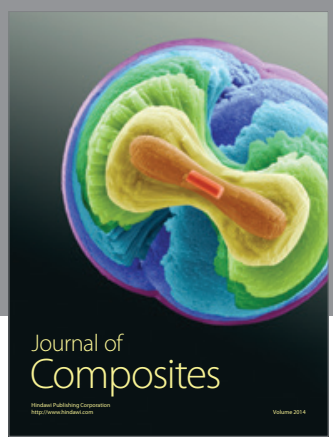
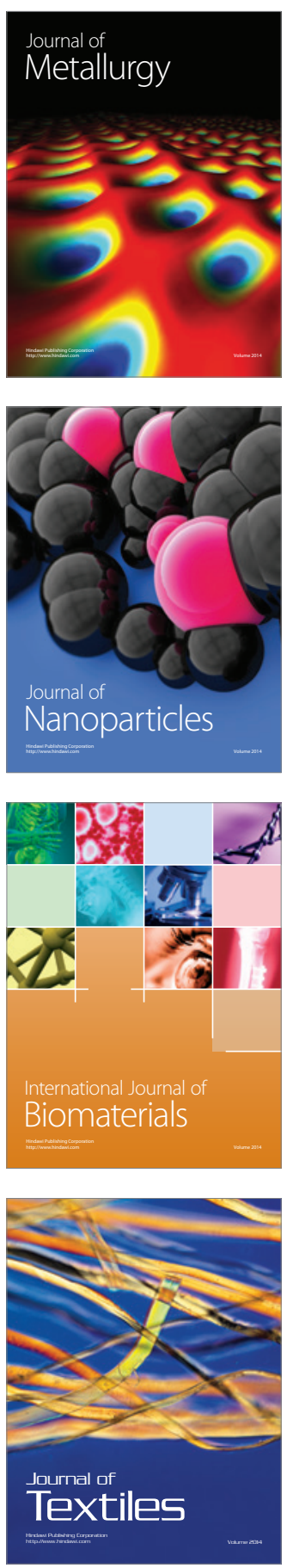